\title{
SCHUR-CONVEX FUNCTIONS RELATED \\ TO HADAMARD-TYPE INEQUALITIES
}

\author{
HUAN-NAN SHI
}

\begin{abstract}
The Schur-convexity on the upper and the lower limit of the integral for a mean of the convex function is researched. As applications, a generalized logarithmic mean with a parameter is obtained and a relevant double inequality that is a extension of the known inequality is established.
\end{abstract}

Mathematics subject classification (2000): 26D15, 26A51.

Key words and phrases: Schur-convex function, inequality, Hadamard's inequality; generalized logarithmic mean.

\section{REFERENCES}

[1] S. S. DRAGOMIR, Two mappings in connection to Hadamard's inequalities, J. Math. Anal. Appl. 1992, 167(1): 49-56

[2] G. S. YANG AND M. C. Hong, A note on Hadamard's inequality, Tamkang. J. Math. 1997, 28 (1): 33-37

[3] S. S. DRAGOMIR, Further properties of some mappings associated with Hermite-Hadamard's inequalities, Tamkang. J. Math. 34(1)(2003), 45-57

[4] N. ElezOVIĆ AND J. PEČARIĆ, A note on Schur-convex fuctions, Rocky Mountain J. Math. 2000, 30 (3): $853-856$.

[5] B. Y. WANG, Foundations of Majorization Inequalities, Beijing Normal Univ. Press, Beijing, China, 1990. (Chinese)

[6] J. C. KUANG, Applied Inequalities, (Chang yong bu deng shi) 3nd ed., Shandong Press of science and technology, Jinan, China, 2002. (Chinese).

[7] A. W. MARShall AND I. OlKIn, Inequalities: Theory of majorization and its application, New York: Academies Press, 1979.

[8] B. Ostle AND H. L. Terwilliger, A companion of two means, Proc. Montana Acad.Sci. 1957, 17(1): $69-70$ 